McIntire et al (1968) described an index of the efficiency of responding under a free operant avoidance schedule as: (Number of shocks received/Maximum possible shocks) $X$. [(Total responses + Minimum responses for total avoidance)/Minimum responses for total avoidance]. Values of this index for each $S$ under all conditions are also shown in Table 1. There was no differential effect on this variable, however (Friedman two-way analysis of variance, $\chi^{2}=7.5, p=0.052$ ). This was largely due to the results of $S 546$, who gave virtually no change in the index between conditions.

\section{DISCUSSION}

In three of the four rats, response-contingent shocks on a FI schedule, in addition to those programmed on the avoidance baseline, led to an increase in responding. It thus seems that this effect is not limited to the various species of monkeys. The usual effect of noncontingent shock in increasing response rate was again confirmed, and noncontingent shock increased responding more than a FI schedule of response-contingent shock at the same shock rate.

Again in three cases, a FR schedule of response-contingent shock led to a decrease in responding whereas a similar FI schedule at the same rate of shock presentation and in the same $S$ led to an increase. This indicates that, although the rate of presentation of response-contingent shock may determine whether an increase or a decrease in responding occurs (Kelleher \& Morse, 1968), the schedule of shock presentation, itself, is an important factor.

This investigation confirmed the main findings of McIntire et al (1968). There were two differences, however. First, the Ss in this experiment were generally more efficient in responding to avoid shocks as measured by their efficiency index. McIntire et al (1968) also found that the efficiency index showed responding under noncontingent additional shocks to be more efficient and responding under FR response-contingent shocks to be less efficient than the baseline responding. Here, although the results for the noncontingent shock procedure were confirmed, two Ss showed less efficient responding under the FR condition, but the other two gave slight increases in efficiency. The present results seem to lie between those of McIntire et al (1968) and those of Sandler et al (1966). The latter, when using marmoset monkeys in a similar situation, were able to report that their Ss established "... an optimal balance ... between adequate avoidance responding and minimal exposure to punishment contingencies."

Which response-contingent shock procedures are defined as punishment procedures depends on the definition of punishment that is adopted. If a functional definition is accepted, e.g., ". . . punishment is a reduction of the future probability of a specific response as a result of the immediate delivery of a stimulus for that response [Azrin \& Holz, 1966,p. 381]," then the FR shock schedules, and in one case (S 542) the FI schedule, were punishment procedures. Any possible punishing effect of the FI schedule in the other cases was masked by more powerful variables. If a definition based on the concept of a reinforcer is accepted, e.g., ". . . withdrawing a positive reinforcer or presenting a negative ... appear to constitute the field of punishment [Skinner, 1953, p. 185]," then all the response-contingent shock procedures are punishment procedures. In this case, three of the eight punishment procedures (the FI schedules of shock presentation for Ss 541 , 546, and 544) demonstrate "paradoxical" effects or the ineffectiveness of punishment.

\section{REFERENCES}

AZRIN, N. H., \& HOLZ, W. C. Punishment. In W. K. Honig (Ed.), Operant behavior: Areas of research and application. New York: Appleton-Century-Crofts, 1966. Pp. 380-447. KELLEHER, R. T., \& MORSE, W. H. Schedules using noxious stimuli. III. Responding maintained with response-produced electric shock. Journal of the Experimental Analysis of Behavior, 1968, 11, 819-838.
KELLEHER, R. T., RIDDLE, W. C., \& COOK, L. Persistent behavior maintained by unavoidable shocks. Joumal of the Experimental Analysis of Behavior, 1963, 6, 507-517.

MCINTIRE, R. W., DAVIS, H., COHEN, S. I., \& FRANCH, E.O.Sidman avoidance performance under punishment and non-contingent shock conditions. Psychological Reports, 1968, 22 897.903.

McKEARNEY, J. W. Fixed-interval schedules of electric shock presentation: Extinction and recovery of performance under different shock intensities and fixed-interval durations. Joumal of the Experimental Analysis of Behavior, 1969, 12,301-313.

MORSE, W. H., MEAD, R. N., \& KELLEHER, R. T. Modulation of elicited behavior by a fixed-interval schedule of electric shock presentation. Science, 1967, 157, 215-217.

POWELL, R. W., \& MORRIS, G. Continuous punishment of free operant avoidance in the rat. Journal of the Experimental Analysis of Behavior, 1969, 12,149-157.

SANDLER, J., DAVIDSON, R. S., \& HOLZSCHUH, R. D. Effects of increasing punishment frequency on Sidman avoidance behavior. Psychonomic Science, 1966, 5, 103-104.

SIDMAN, M. Two temporal parameters of the maintenance of avoidance behavior by the white rat. Journal of Comparative \& Physiological Psychology, 1953, 46, 253-261.

SIDMAN, M., HERRNSTEIN, R. J., \& CONRAD, D. G. Maintenance of avoidance behavior by unavoidable shocks. Journal of Comparative \& Physiological Psychology, 1957, 50, 553-557. SXINNER, B. F. Science and human behavior. New York: Macmillan, 1953.

\title{
A further analysis of conjunctive reinforcement schedules ${ }^{1}$
}

\section{E. WADE HITZING and JAMES H. KAYE, Kalamazoo State Hospital, Kalamazoo, Mich. 49001}

Pigeons were first tested on a fixed-interval 3-min reinforcement schedule. The simple fixed interval was then changed to a conjunctive schedule by the addition of a fixed-ratio requirement. On the conjunctive schedule, responding was reinforced only after at least 3 min had elapsed and after the emission of some minimum number of responses. The two initial ratio requirements programmed produced an increase in response rate, but a third addition to the response requirement resulted in a total cessation of responding.

In a conjunctive (conj) fixed-interval (FI), fixed-ratio (FR) schedule, responding is reinforced only after the passage of a fixed time period and the emission of some minimal number of responses. Previous research by Herrnstein \& Morse (1958) has shown that a conj FI FR schedule maintains a lower rate of responding than a simple FI of the same duration. It has not yet been 

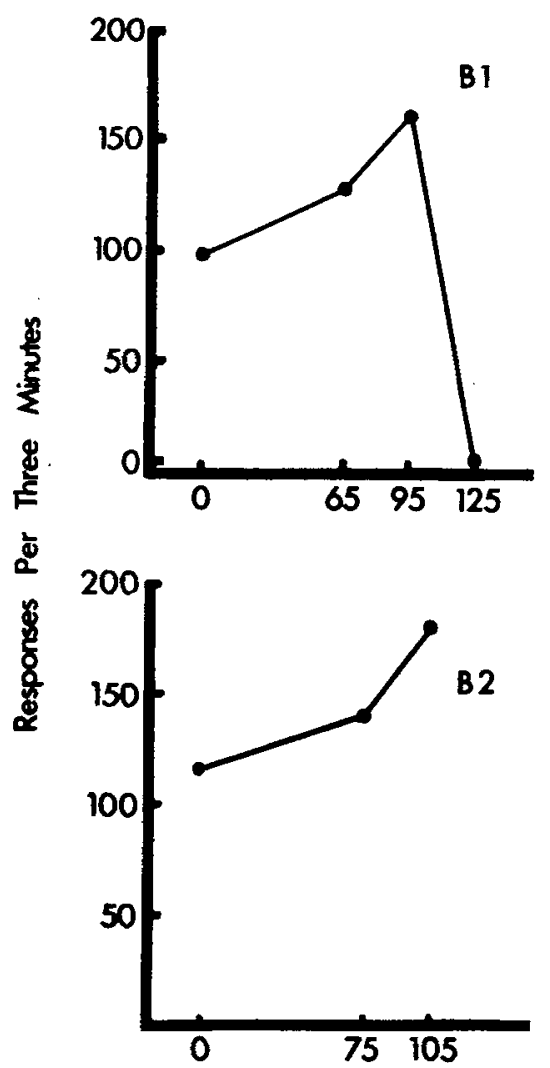

Responses Required Per Interval

Fig. 1. Mean responses per $3 \mathrm{~min}$ for both Ss plotted as a function of the number of responses required per interval. Points plotted at zero on the abscissa refer to the simple fixed-interval schedule.

determined whether the preceding results are general for other possible values of conjunctive schedules. The present research presents some data gathered using a shorter FI value than that of Hermstein \& Morse (1958).

\section{METHOD}

Two experimentally naive white Carneaux pigeons (B1 and B2) maintained at $70 \%$ of their ad lib body weights, served as Ss. The Ss were housed in separate home cages where they had free access to water and grit.

The experimental chamber included a single transilluminated response key located $83 / \mathrm{in}$. above the floor and $4 \mathrm{in}$. directly above the grain hopper. A single houselight located in the rear of the chamber offered additional illumination. A 3-sec hopper time was employed during which the feeder was illuminated and the other chamber lights were extinguished. A 1-min time out (TO) period with all chamber lights extinguished was programmed immediately prior to and at the end of each experimental session.

The Ss were first shaped to peck the response key. After approximately 200 continuous reinforcements, the schedule was changed to a simple fixed interval. The value of the FI was gradually increased both within and between sessions until the terminal FI 3 schedule was achieved. The daily sessions were terminated after either 25 reinforcements or $3 \mathrm{~h}$, whichever occurred first. After the response rate stabilized on the FI 3 , the schedule was changed to conj FI 3 FR 65 for BI and conj FI 3 FR 75 for B2. The ratio requirements of the initial FR values were determined by first calculating a frequency distribution of the number of responses in each $\mathrm{FI}$ interval for the last three baseline sessions. The FR value corresponding to the 10 th percentile of this frequency distribution was then determined. This procedure initially provided the $S$ with relatively few contacts with the added FR contingency, a condition which in the past was said to effect a lowering of previous steady-state FI performance (Hermstein \& Morse, 1958). When the response rate stabilized at these values, the reinforcement schedule was changed to conj FI 3 FR 95 for B 1 and conj FI 3 FR 105 for B2. A further increase to conj FI 3 FR 125 was carried out after this for B1. It was not possible to further increase the FR requirement for $B 2$ because the $S$ died after 10 days on the conj FI 3 FR 105.

\section{RESULTS}

The average number of responses per session, for each $\mathrm{S}$, under both the baseline and conjunctive schedules can be seen in Fig. 1; each of the data points is the mean of the last 5 days under each condition. There was a systematic increase in responses per session, for both birds, after the addition of the first two ratio requirements. During the 10th day on conj FI 3 FR 125, B1 stopped responding after receiving only 17 reinforcements. During the following four sessions, B1 emitted increasingly lower rates of responding, and for the next three sessions did not respond at all. B2's response rate was still increasing on the conj FI 3 FR 105.

Figure 2 shows the interreinforcement distribution of responses, for both Ss, under each of the schedule conditions. Even though the total number of responses increased, there was very little systematic change in the temporal distribution of responses.

\section{DISCUSSION}

The increase in response rate, for both Ss, under the first two FR requirements does not agree with the results reported in previous research. Hermstein \& Morse (1958), using a 15-min FI schedule, reported that the addition of a ratio requirement ( 40 responses) which was less than $20 \%$ of the average simple FI response rate resulted in a
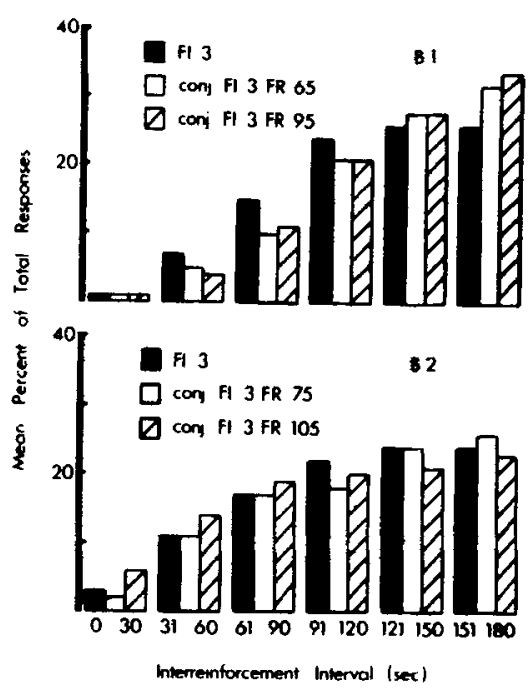

Fig. 2. Interreinforcement distribution of responding, for both Ss, under the simple FI 3 and the first two ratio requirements. The numbers plotted on the absciss refer to the successive 30-sec segments of the 3-min interreinforcement interval.

significant decrease in response rate and an increase in the average interreinforcement interval. In this study, the addition of ratio requirements which were more than $50 \%$ of the simple FI 3-min response rates resulted in significant increases in response rate. Hermstein and Morse also reported that additional increases in the ratio requirement resulted in further decreases in response rate. In this study, additional increases in the FR requirement initially produced increases in response rate but ultimately resulted in a complete cessation of responding. The principal reason for the differences in the results in these two studies is probably the length of the FI requirements of the baseline schedule of reinforcement. The data indicate that the occurrence of intervals containing only a few responses, which result in a high probability of reinforcement, are not critical to the maintenance of responding on short FI schedules. The results also show that it may not be correct to typify a conjunctive schedule as maintaining "a lower overall rate of responding than does a simple FI of the same duration [Reynolds, 1968, p. 82] ."

\section{REFERENCES}

HERRNSTEIN, R. J., \& MORSE, W. H. A conjunctive schedule of reinforcement. Journal of the Experimental Analysis of Behavior, 1958, 1, 15-24.

REYNOLDS, G. S. A primer of operant conditioning. Glenview: Scott, Foresman, 1968.

\section{NOTE}

1. The preparation of this report was facilitated by Research Grant No. 103-1800-176B from the Michigan State Department of Mental Health. 